\title{
Extent of predation bias present in migration survival and timing of Atlantic salmon smolt (Salmo salar) as suggested by a novel acoustic tag
}

\author{
Jason Daniels ${ }^{1^{*}} \mathbb{0}$, Stephen Sutton ${ }^{1}$, Dale Webber ${ }^{2}$ and Jonathan Carr ${ }^{1}$
}

\begin{abstract}
Background: Acoustic telemetry is increasingly being used as a tool to measure survival, migration timing and behaviour of fish. Tagged fish may fall prey to other animals with the tag continuing to be detected whilst it remains in the gastrointestinal tract of the predator. Failure to identify post-predation detections introduces "predation bias" into the data. We employed a new predator tag technology in the first known field trial to understand the extent these tags could reduce predation bias in Atlantic salmon (Salmo salar L.) smolt migration through a 65-km zone beginning in freshwater and extending through an estuary. These tags signal predation by detecting a pH change in the predators' gut during digestion of a tagged prey. We quantified survival and timing bias by comparing measurements from non- and post-predated detections of tagged individuals' to only those detections where predation was not signalled.
\end{abstract}

Results: Of the 50 fish tagged, 41 were detected with 24 of these signalling as predated. Predation bias was greatest in the upper estuary and decreased towards the bay. Survival bias peaked at $11.6 \%$ at river $\mathrm{km} 54$. Minimum and maximum migration time were both biased long and were $16 \%$ and $4 \%$ greater than bias corrected timing at river $\mathrm{km} 66$ and 54 , respectively. After correcting for bias, the apparent survival from release through freshwater and estuary was $19 \%$ and minimum and maximum migration timing was 6.6 and 7.0 days, respectively.

Conclusions: Using this tag, we identified a high proportion of predation events that may have otherwise gone unnoticed using conventional acoustic tags. Estimated survival presented the greatest predation bias in the upper estuary which gradually declined to nearly no apparent bias in the lower estuary as predated tags failed through time to be detected. This is most likely due to tag expulsion from the predator between or upstream of receiver arrays. Whilst we have demonstrated that predation can bias telemetry results, it appears to be rather short-lived given the apparent retention times of these tags within the predators introducing the bias.

Keywords: Atlantic salmon smolt, Predator tag, Bias, Survival, Migration timing

\footnotetext{
*Correspondence: jdaniels@asf.ca

${ }^{1}$ Atlantic Salmon Federation, 15 Rankine Mill Road, Chamcook, NB E5B

3A9, Canada

Full list of author information is available at the end of the article
} 


\section{Background}

Acoustic telemetry has become an invaluable tool for observing migration timing, distribution, behaviour, and survival of aquatic organisms, most notably for teleost fishes [1]. The ongoing miniaturization of acoustic transmitters (hereafter: tags) allows for the study of smaller individuals, such as the parr and smolt stages of anadromous salmonids. A characteristic problem associated with tagging small fish is that they may fall prey to other animals with the tag continuing to be detected whilst it remains in the gastrointestinal tract of the predator $[2,3]$. Failure to identify post-predation detections introduces "predation bias" into the data [4].

With the increased adoption of acoustic telemetry as a tracking method came the development of techniques to classify detections resulting from a predator's movement as opposed to that of the individual tagged. These classification techniques evolved from observations [5], towards subjective and qualitative analyses [6], and more recently, to quantitative approaches $[2,4,7]$. Whilst more recent quantitative methods are repeatable and allow for the removal of subjective classification, they are still limited in several ways. First, all current quantitative methods classify predated versus non-predated individuals based on behavioural differences between the target species and potential predators. This implies that suspected predatory species must also be tagged and detected within the extent of the study. Second, most classification methodologies identify if an individual was predated; however, they do not define when the predation occurred. As a result, accounting for the predation event requires either a subjective decision as to when the event occurred or the removal of all detections from the individual suspected to have been predated, thereby reducing valuable sample size.

Recent technological innovations have allowed for the production of a novel acoustic tag type, referred to as a predator tag, that directly detects the occurrence of a predation event. This tag signals consumption events based on a change in identification code triggered by the change in $\mathrm{pH}$ associated with the predator's gastrointestinal tract [8]. Although there is still a time lag associated with detection of a predation event (due to the time necessary for digestion, signal switching, and subsequent detection), these tags possess the potential to segregate pre- and post-predation detections within the temporal and spatial extent of the study; an advantage not held by any known behaviour-based model. Thus, predator tags permit the removal of some degree of predation bias from migration metrics. Furthermore, if the goal is to identify the predation rate of the target species without the need to identify the predatory species, then there is no requirement for knowledge of the behaviours, and therefore tagging, of predatory species in conjunction with the target species.

Our understanding of the rates of Atlantic salmon (Salmo salar L.) predation and survival throughout the Miramichi River, estuary and bay has increased through recent studies. Chaput et al. [9], described the rate of migration survival from release through the river, estuary and bay, and the Gulf of St. Lawrence (GoSL) annually from 2004 to 2008 and 2013 to 2016 for the Northwest Miramichi River (NW) smolts. This study identified a relatively recent and substantial reduction in the survival of smolts through the estuarine and bay environments. Between 2004 and 2008, the average estimated survival from release to the GoSL was approximately $70 \%$. In more recent years, 2013 to 2016, estimated survival to the same location was approximately $30 \%$ on average. Daniels et al. [7] developed a behaviourbased model to estimate the rate of predation on Atlantic salmon smolts by striped bass (Morone saxitilis) in the same system. That study presented estimated predation rates ranging between 7 and $18 \%$ for NW smolts migrating through the estuary and bay between 2013 and 2016 . Given the variable rates of apparent predation and survival, an unknown degree of predation bias may be present in the inferred survival to and through the estuary by Chaput et al. [9] for Miramichi smolts. Any potential bias in these estimates may exacerbate the declining trend in survival through the estuary and Miramichi Bay.

The objective of this study was to understand the extent to which predator tags could reduce predation bias in a real-world setting. We quantified the degree of bias introduced to survival and migration timing estimates through predation by surgically implanting Amirix/Vemco V5 predator tags (Bedford, Nova Scotia, Canada) into smolts captured and released in the NW. In addition, we employed this new tag technology in the first known fieldbased study to broaden our understanding of the rate of predation on Atlantic salmon smolts as they migrated through the lower reaches of the freshwater and estuarine environments of the NW to the mouth of Miramichi Bay.

\section{Methods \\ Description of the Miramichi River system}

The Miramichi River system has a catchment area of roughly $14,000 \mathrm{~km}^{2}$ (Fig. 1). There are two main branches of the Miramichi River; the Southwest Miramichi River (SW) and the NW, in which this study was performed. The NW estuary, as we have defined it, extends approximately 20 river $\mathrm{km}$ upstream of the confluence where both branches drain into a single estuary that enters the Southern GoSL [10] (Fig. 1). The NW is the smaller of the two branches with approximately half the mean yearly discharge as the SW $\left(86 \mathrm{~m}^{3} \times \mathrm{s}^{-1}\right)$. 


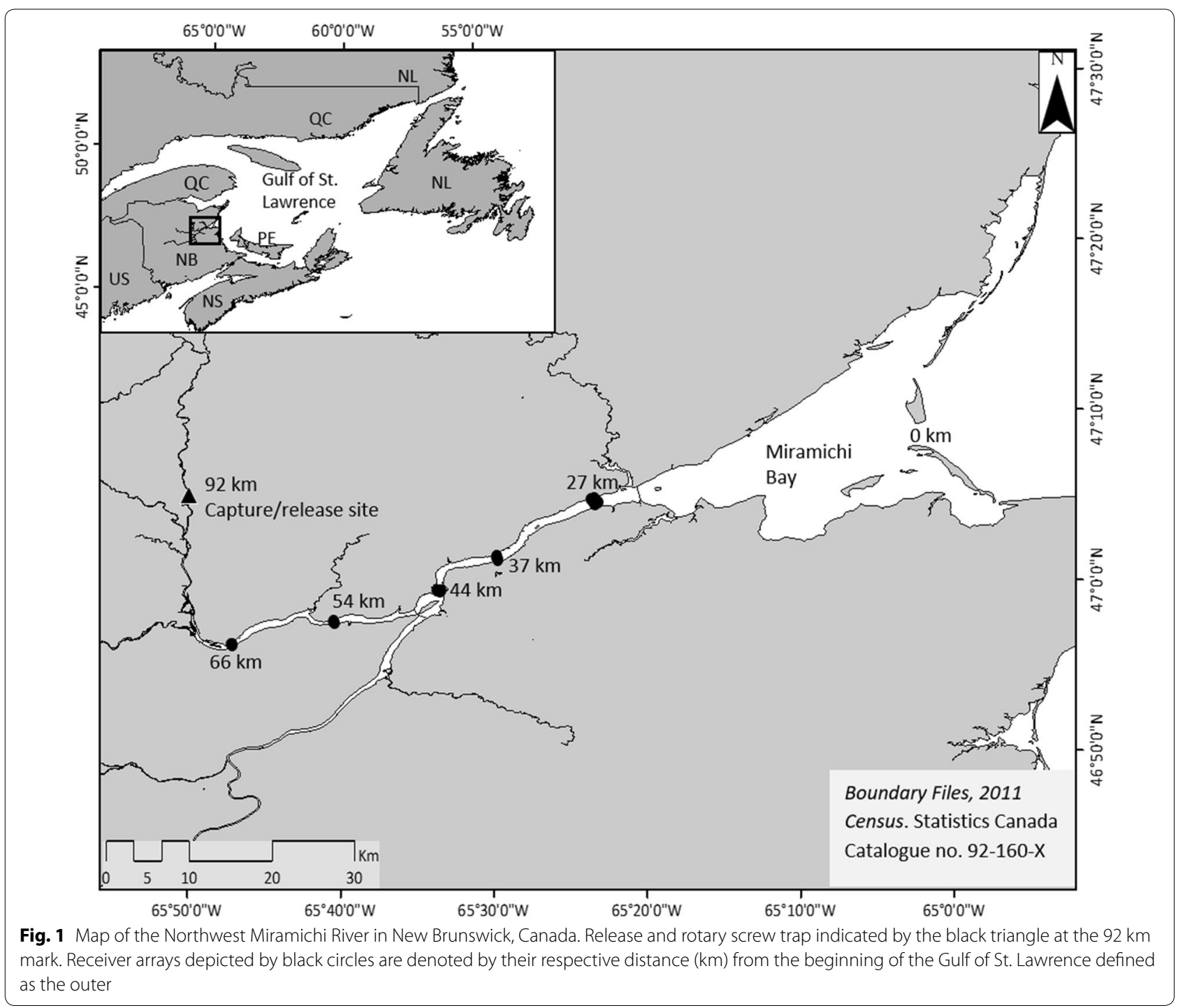

\section{Description of the tagging protocols}

Atlantic salmon smolts were collected using rotary screw traps, located at the NW $\left(47.094277^{\circ} \mathrm{N}, 65.837024^{\circ} \mathrm{W}\right.$; Fig. 1). The rotary screw traps operating in the NW were primarily deployed for the purposes of a concurrent study. A random sample of 50 smolts was selected for tagging between May 17 and May 29, 2017. These dates represented the first possible date of smolt capture in rotary screw traps to the point where smolts could reliably be caught before the end of the smolt run. The number of smolts tagged per day was selected to mirror the distribution of the smolt run, which was subjectively based on observations from biologists working the rotary screw traps. Due to later than normal deployment of the rotary screw traps, a larger number of smolts were tagged on day 1 (May 17) in comparison to remaining days. The final release date for acoustic predator tagged smolts occurred on May 29 (Fig. 2). Amirix/Vemco V5 predator tags $(5.6 \mathrm{~mm}$ diameter by $12.7 \mathrm{~mm}$ length, $0.68 \mathrm{~g}$ in air) were uniquely coded and programmed to emit signals at random time intervals between 15 and $25 \mathrm{~s}$ at a frequency of $180 \mathrm{kHz}$.

All smolts sampled for surgery were held in in-stream tanks for 20-24 h to allow for digestion of stomach contents. Smolts were anaesthetized using clove oil $\left(0.2 \mathrm{~mL} \times \mathrm{L}^{-1}\right.$ concentration) until loss of equilibrium and very little gill movement was observed (generally 3-5 min). Fork length $(\mathrm{cm})$ was taken before the fish was placed ventral side up on a v-shaped operating board. All surgical tools and tags were disinfected in anhydrous ethyl alcohol and rinsed in distilled water prior to each surgery. An approximately $7 \mathrm{~mm}$ incision was made 


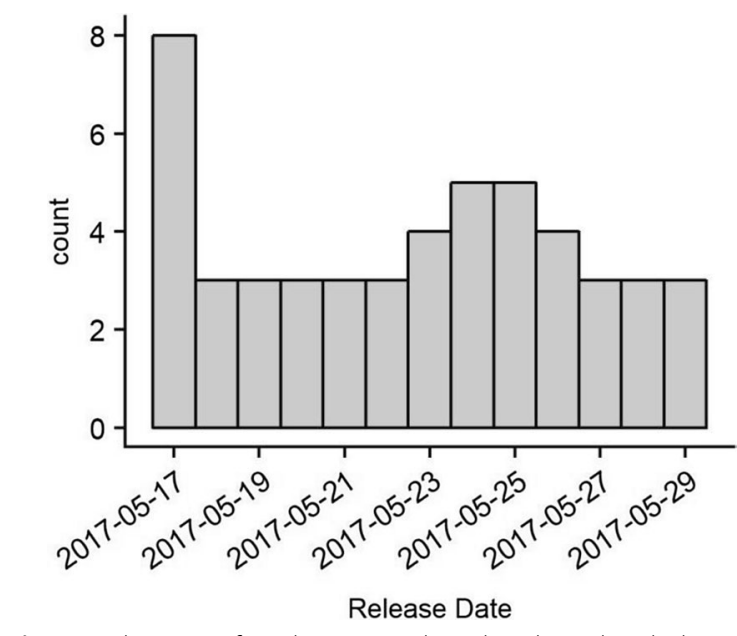

Fig. 2 Daily count of predator tagged smolts released each day

along the mid-ventral line about $20 \mathrm{~mm}$ anterior to the pelvic girdle. Tags were inserted via the incision into the abdominal cavity of the fish. The fish's body and gills were continuously irrigated during the surgery. Incisions were sealed with a single stitch using 4/0 non-absorbable black monofilament nylon sutures with 19 -mm reverse cutting blades. Fish were placed in an aerated recovery bath for observation. Once equilibrium had been restored, fish were transferred to in-river holding tanks approximately $100 \mathrm{~m}$ downstream of the rotary screw trap and held for a minimum of $1 \mathrm{~h}$ before release at river $\mathrm{km} 92$. With the exception of the smolts collected for this study, fork lengths were not measured and daily counts of smolts captured in the smolt wheel were not taken. The fork lengths of smolts randomly selected for tagging were comparable to mean fork lengths of smolts sampled from this river in the previous studies [11, 12] (Fig. 3).

\section{Description of the receiver deployment}

Amirix/Vemco hydro-acoustic receivers (model VR2W180) were deployed within the Miramichi River system to record smolt passage. For this study, five sequential receiver arrays were moored approximately 10 river $\mathrm{km}$ apart ranging between the NW head of tide region (66 km mark) to the beginning of Miramichi Bay (27 km mark; Fig. 1). At the most downstream receiver array, a second array was positioned approximately $1 \mathrm{~km}$ further downstream to disentangle survival from the detection efficiency (see "Survival analyses"). For each array, receiver spacing was determined by drifting V5 sentinel tags from 0 to $300 \mathrm{~m}$ away from a receiver and using logistic regression to calculate the probability of detecting a single transmission $\left(p\left(\right.\right.$ Det $\left.\left._{\text {single }}\right)\right)$ as a function of distance. Receiver positions were adjusted

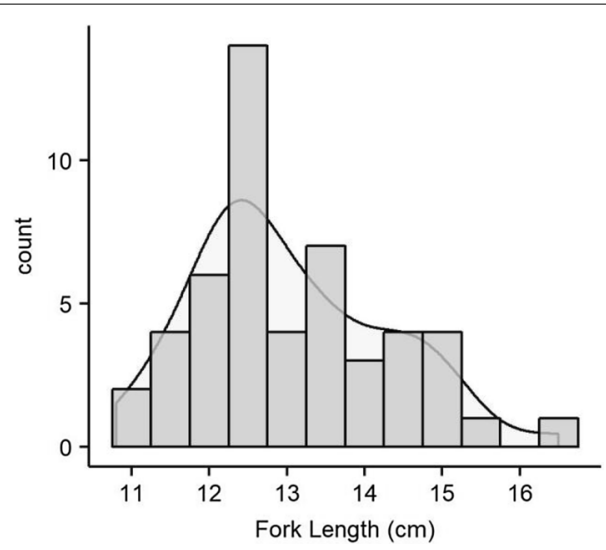

Fig. 3 Distribution of fork lengths from smolts randomly selected for predator tagging. Histogram reflects $0.5-\mathrm{cm}$ bins. Smoothed line is the fit kernel density estimate from the length distribution

to ensure that the receivers were no further than the distance of $p\left(\right.$ Det $\left._{\text {single }}\right)=0.50$ to shore or twice that distance to any other receiver. The resulting mean spacing between receivers was approximately $170 \mathrm{~m}$. All receivers were attached to moorings consisting of varying weight anchors (depending on current and possible surface conditions), line and surface floats. Receivers were attached approximately $4 \mathrm{~m}$ below the surface floats. Sinking line was used from the surface floats to a nylon swivel located below the receiver, which in turn was attached to the anchor with floating line.

\section{Bias measurements}

To quantify the extent of bias introduced as a result of predator movement being detected (i.e. predation bias), we segregated the detection data into two groups. The 'biased' group represents a naïve approach to the detection data by not differentiating between pre- and postpredation detections. This is the typical fashion in which acoustic telemetry data without a predation sensor would be analysed. The 'clean' group represents detection histories after the removal of all post-predation detections from individual tags that signalled as being predated. After segregating the data into these two groups, we then measured the difference between group mean apparent survival and migration timing. For both apparent survival and migration timing, we also calculated the area of the clean groups' kernel density estimate (kde) not overlapped by the biased groups' kde for each parameter. This was performed by estimating a joint density for each comparison (i.e. survival and minimum/maximum migration time) and calculating the area of overlap using the 'Overlap' package [13] in R [14]. Given that we are describing the degree of bias present from our population of tagged smolts, we make no attempt to identify 
statistically relevant or meaningful differences between groups.

\section{Migration timing}

Quantifying migration timing using acoustic telemetry can be done in various ways. For example, migration timing between receivers could be calculated as the difference between the last detection at array $i$ to the first detection at array $i+1 \ldots m$, which we define as the minimum time between arrays. Migration timing could also be quantified as the first detection at array $i$ to the last detection at array $i+1 \ldots m$, which we define as the maximum time between arrays. It is important to note that under the above-mentioned examples (or any combination of them), the time between detections cannot be summed across multiple successive arrays to give cumulative migration timing when directional changes or residency is present in the detection history because periods of time would be unaccounted for or double counted. To account for nonunidirectional movement and residency, migration timing must be quantified in a cumulative manner from a reference point. In this study, we quantified the minimum and maximum migration timing as the time from the release location to/through each receiver array. It is also important to acknowledge that uncertainty exists in the locations of detections whilst approaching (or departing) a receiver array's range of detection and a relatively small degree of error may exist as we assumed that detections occurred at the position of the receivers comprising the array.

\section{Survival analyses}

A Bayesian state-space formulation of the Cormack-JollySeber (CJS) model was used to estimate the probability of detection $(p)$ at, and survival $(\phi)$ to, each array $[15,16]$. The unobserved survival (i.e., state) process assumes that fish $i$ marked at array $g$ may survive to array $g+1$ with probability $\phi_{g}$ or die with probability $1-\phi_{g}$. The parameter $\phi_{g}$ is modelled as Bernoulli random variable and is conditional on the latent variable $z(i, g+1)$ (Eq. 1). This process continues through time $g+1,2, \ldots, x$ until the fish is dead or it reaches the last receiver array.

$$
z(i, g+1) \mid z(i, g) \sim \operatorname{Bernoulli}\left(z(i, g) \emptyset_{g}\right) .
$$

Tagged smolts alive at $g+1$ may be detected with probability $p_{g+1}$ or not detected with probability $1-p_{g+1}$. This observed process of re-detections is also parameterized as a Bernoulli random variable conditional on $z(i, g+1)$ (Eq. 2). Therefore, $z(i, g)$ defines the true state of fish ${ }_{i}$ at gate ${ }_{g}$

$$
y(i, g) \mid z(i, g) \sim \operatorname{Bernoulli}\left(z(i, g) p_{g}\right)
$$

This model was formulated to estimate unique survival parameters for each group (i.e., the biased group and the clean group) to each successive gate along the migration. Uninformative priors for both the probability of detection and survival were used. The model was written in OpenBUGS (version 3.2.3) and run with three chains of 50,000 iterations, a thinning rate of 5 , and a burn-in of 25,000 , for a total of 75,000 MCMC samples in the posterior distribution. Model convergence was based on visual inspection of MCMC sample overlap from differing chains, as well as through the Gelman-Rubin statistic. All analyses were conducted in R [14].

\section{Results}

Detections and migration timing

Of the 50 smolts tagged and released at river $\mathrm{km} \mathrm{92,}$ 41 individuals were detected at receiver arrays within the study site. As expected, the number of individuals detected at successive receiver arrays decreased downstream for both groups; however, comparatively fewer individuals were detected from the clean group (Table 1). Of the 41 tags with detections, 24 (59\%) were registered as predated, with five of these being detected exclusively as post-predated. Nine (22\%) tags were detected

Table 1 Count of predator tagged smolts detected for both the biased and clean groups detection histories at successive

\begin{tabular}{|c|c|c|c|c|c|c|c|c|}
\hline \multirow{2}{*}{$\begin{array}{l}\text { Location } \\
\text { Array (km) }\end{array}$} & \multicolumn{2}{|c|}{ Tags detected (\%) } & \multicolumn{2}{|c|}{$\begin{array}{l}\text { Inferred mean cumulative } \\
\text { survival }\end{array}$} & \multicolumn{2}{|c|}{$\begin{array}{l}\text { Maximum migration time } \\
\text { to array (day) }\end{array}$} & \multicolumn{2}{|c|}{$\begin{array}{l}\text { Minimum migration time } \\
\text { to array (day) }\end{array}$} \\
\hline & Biased group & Clean group & $\begin{array}{l}\text { Group mean } \\
\text { difference }\end{array}$ & KDE shift & $\begin{array}{l}\text { Group mean } \\
\text { difference }\end{array}$ & KDE shift & $\begin{array}{l}\text { Group mean } \\
\text { difference }\end{array}$ & KDE shift \\
\hline 66 & $41(82)$ & $36(72)$ & 0.093 & 0.566 & 0.558 & 0.112 & 0.007 & 0.021 \\
\hline 54 & $30(60)$ & $24(48)$ & 0.115 & 0.588 & 0.412 & 0.095 & 0.175 & 0.048 \\
\hline 44 & $17(34)$ & $15(30)$ & 0.062 & 0.351 & 0.432 & 0.146 & 0.074 & 0.047 \\
\hline 37 & $16(32)$ & $13(26)$ & 0.059 & 0.370 & 0.182 & 0.098 & 0.019 & 0.042 \\
\hline 27 & $12(24)$ & $11(22)$ & 0.022 & 0.166 & 0.180 & 0.097 & 0.078 & 0.058 \\
\hline
\end{tabular}
acoustic receiver arrays

The extent of bias present in migration timing and apparent survival at successive acoustic receiver arrays are presented as the difference in means and the proportion of the joint kernel density estimate (KDE) areas for both groups that does not overlap 
post-predation at more than one receiver array. The remaining 15 (37\%) tags were detected post-predation at a single array only. Of the $17(41 \%)$ tags that did not signal as predated, eight (19\%) were detected at the last downstream receiver array (arrays $27 / 26 \mathrm{~km}$ ) and presumed successful in migrating through the estuary. For the remaining nine (22\%) non-predated tags, three, three, two, and one $\operatorname{tag}(\mathrm{s})$ were last detected at arrays $66 \mathrm{~km}$, $54 \mathrm{~km}, 44 \mathrm{~km}$, and $37 \mathrm{~km}$, respectively. Univariate logistic regression revealed no evidence of a relationship between the probability of predation in relation to smolt fork length $(P=0.785)$ or release date $(P=0.227)$.

Three tags detected as post-predations had final detections on a single receiver for 19, 35 and 37 days, suggesting post-predation tag expulsion or falsely triggered tags in dead fish. For this reason, these tags were removed from the data to present migration timing. To present the time between first and last post-predation detection, the single post-predated tag detected migrating downstream of the final receiver array was removed from the data along with three suspected tag expulsions described above. The mean time span between first and last post-predated tag detections was $17 \mathrm{~h}$ with a median value of $11.3 \mathrm{~h}$ (range $0.1-60.25 \mathrm{~h}$ ). Minimum and maximum migration time were both biased slow. The between group difference in mean migration time (i.e., bias) from release was greater when calculated as the maximum migration time compared to the minimum migration time. Differences in mean migration time between groups to each array ranged from 0.01 to 0.18 days for minimum migration time and 0.18 days to 0.55 days for maximum migration time. The proportion of the clean groups' kde not overlapped by the biased groups' kde was also greater for maximum migration timing (range 9.5$14.6 \%$ ) compared to minimum migration timing (range 2.1-5.8\%; Fig. 4).

\section{Probability of detection and survival}

Model diagnostics suggested there was sufficient convergence, as MCMC samples were well mixed between the three chains based on visual inspection in addition to Gelman-Rubin statistics being very close to 1 for all parameters monitored. The estimated probability of detection at each of the five arrays was high for both the biased and clean groups, with median estimates generally 0.95 or greater. The one exception occurred at array $44 \mathrm{~km}$ where the estimated median value was 0.83 and 0.88 for the biased and clean groups, respectively (Fig. 5). This location was also the only identified array with imperfect detection, where one undetected tag was detected at a downstream array. Eight tags transmitted as post-predated at an array further downstream than the last pre-predated detection, therefore biasing the

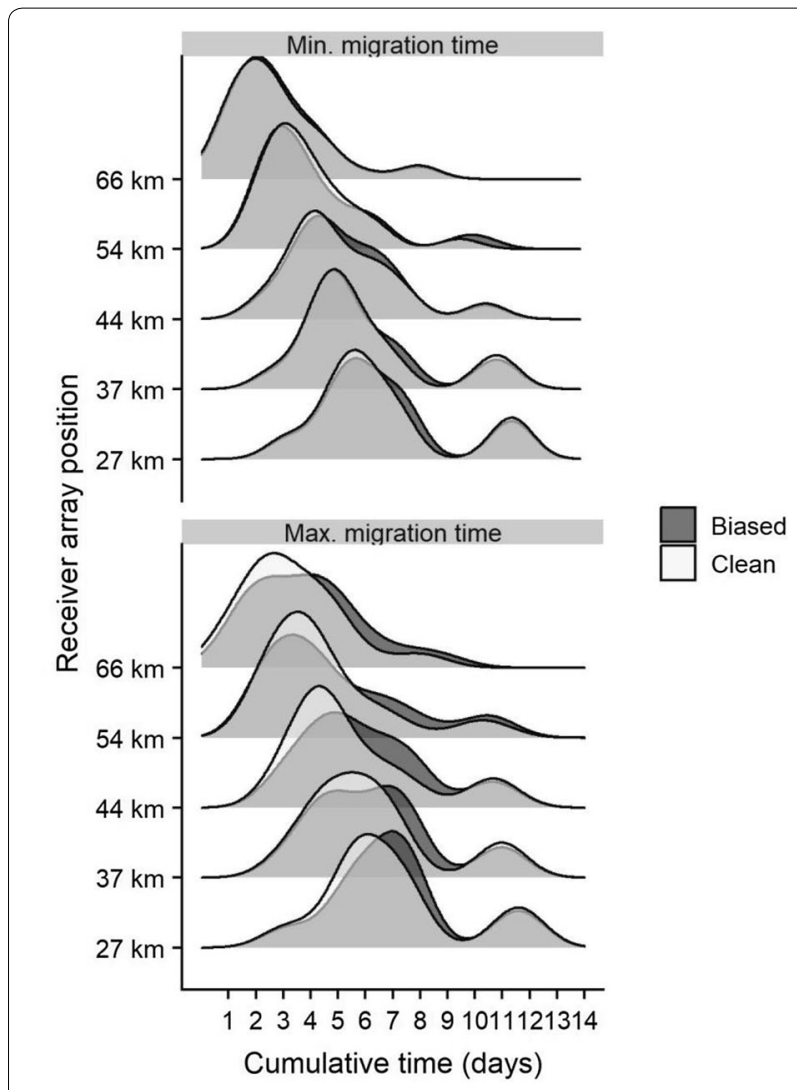

Fig. 4 Distribution in timing from release to the first detection (top panel) and release to last detection (bottom panel) for tags within both the biased group (dark grey distribution) and the clean group to each array through the study site. Times to each array were calculated as cumulative time from release to arrays $66 \mathrm{~km}$ through $27 \mathrm{~km}$

estimated survival to arrays. Apparent survival was lowest between arrays 66 and $54 \mathrm{~km}$ for the biased group and between 92 (release) to $66 \mathrm{~km}$ for the clean group (Table 1). When looking at bias, as quantified through differences in mean apparent survival, a similar geographic trend to that observed for migration timing is observed. Predation bias of mean survival to array $66 \mathrm{~km}$ was $9.4 \%$, peaked at $11.6 \%$ to array $54 \mathrm{~km}$ and incrementally decreased to a low of $2.2 \%$ to array $27 \mathrm{~km}$ (Table 1 ). The proportion of the clean groups' kde not overlapped by the biased groups' kde for inferred survival also exhibited similar geographic trends peaking at array $54 \mathrm{~km}$ $(58.8 \%)$ and decreased to a minimum to array $27 \mathrm{~km}$ (16.6\%; Fig. 6).

\section{Discussion}

Results from this study suggest that predation bias is indeed an issue, especially if survival estimates and timing are to be examined at relatively fine spatial 


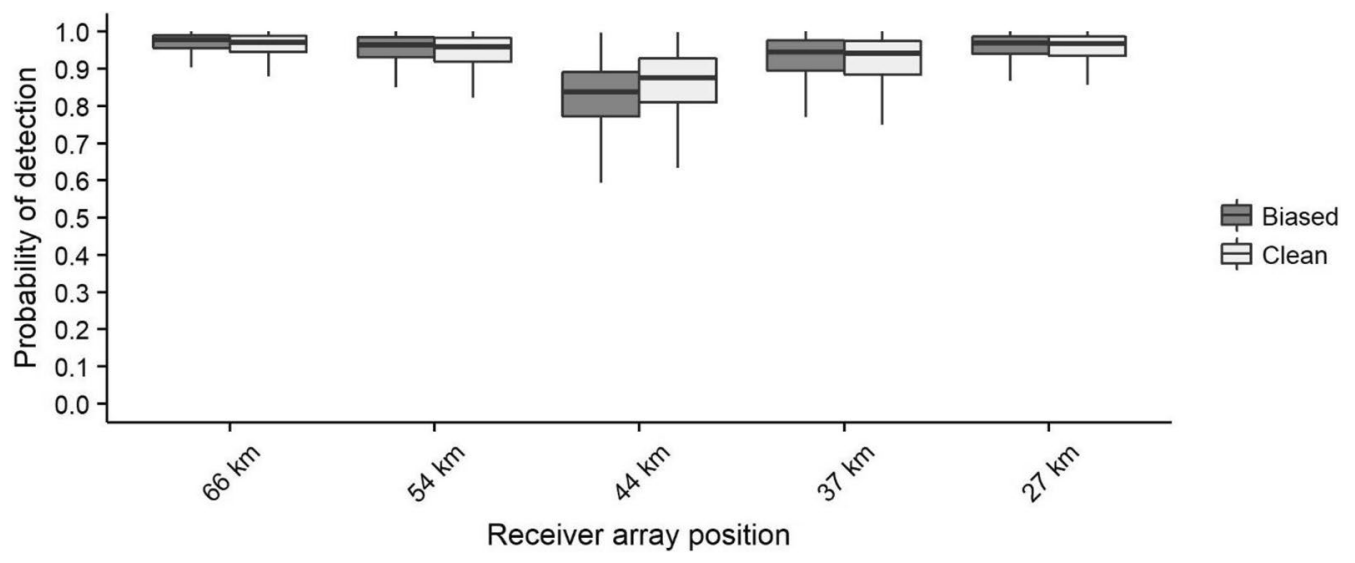

Fig. 5 Posterior distribution of the probability of detection estimated at each array for the biased group (dark grey) and the clean group (light grey)

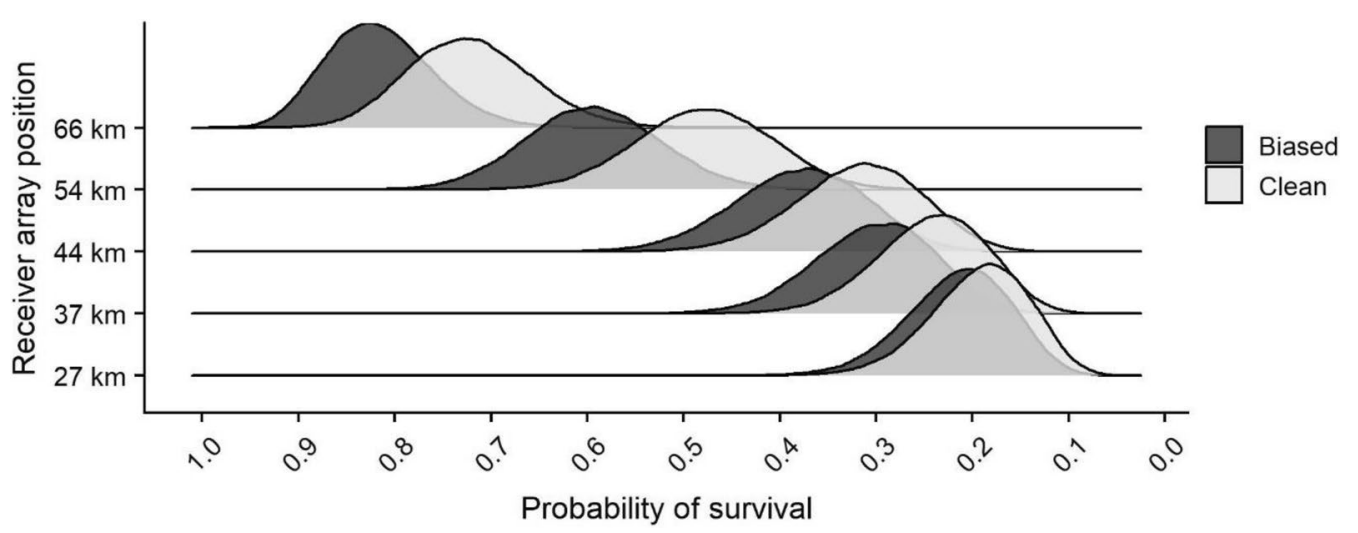

Fig. 6 Posterior distribution of the cumulative probability of survival estimated from release to each array for the biased group (dark grey) and the clean group (light grey)

and temporal resolutions. The extent of predation bias quantified within survival estimates in this study skews the interpretation of where mortality is occurring. We would suggest that the mean rate of mortality was $18 \%$ and $60 \%$ in freshwater and estuarine sections of the river, respectively, if taking a naive stance to predation bias. By accounting for predation bias utilizing this technology, we could infer the mean mortality rate was $28 \%$ and $53 \%$ in freshwater and estuarine sections of the river, respectively. This suggests that whilst a greater proportion of smolts are lost in estuary a substantial portion are still being lost in the freshwater reaches. Chaput et al. [9] estimated migration survival of smolts in the NW from 2004 to 2016 (excluding 2009 to 2012). In their study, survival was estimated from release to array $66 \mathrm{~km}$, array $0 \mathrm{~km}$ (i.e. outer Miramichi Bay), and ultimately to the exit of the GoSL. Apparent survival to array $66 \mathrm{~km}$ was generally quite high from release relative to survival through the estuary and bay. Given the bias found in this study, the potential exists for apparent smolt survival to be relatively poorer in the freshwater region and greater through estuarine and bay regions than was presumed. From a management perspective, identifying where mortality is occurring is crucial if efforts to identify causal factors and mitigate losses are being considered.

The greatest amount of predation bias, as well as the greatest proportion of predation signalling, occurred in the NW estuary. This is perhaps an indicative of the species and/or location of predators within the spatial extent of our study. Striped bass from across the Southern GoSL congregate in the upper NW estuary to spawn in late May early June as smolts are migrating to the ocean. Based on stomach content analysis [17] and concurrent intra-species acoustic telemetry studies [7], striped bass and Atlantic salmon smolt overlap considerably in the estuary of NW. Whilst there was a large degree of uncertainty, the abundance of striped bass aggregating within the NW in 2017 was considerable and was 
estimated at 994,000 (90\% CI 486,400 to 2,063,000; [18]). Within this study, $37 \%$ of tags which signalled as predated were also detected at multiple arrays throughout the system. These are unlikely to be the result of avian or semi-aquatic terrestrial predators because such predators would be expected to remove the tag from the study site and therefore reduce the likelihood of further detections [19]. Whilst speculative, this suggests that these individuals were likely predated by piscine predators such as the highly abundant striped bass. A significant number of smolts likely fall prey to striped bass during the spring migration as suggested by Daniels et al. [7]. It is important to note that apparent predation and the higher extent of bias in the NW portion of the estuary could be a result of the smolts' increased stress associated with the transition from fresh to salt water [20] and the associated morphological/physiologic changes [21, 22]. Susceptibility to predation, and therefore potential bias, may also be exaggerated by ill effects from handling and tagging procedures [23].

The extent of predation bias present is directly related to the time a predator retains an ingested tag in addition to the behaviour exhibited by the predator. For example, if an avian or semi-terrestrial predator removed the tagged smolt from the study site, the expected result would be no further detections, and therefore, no bias introduced. The same could be said for highly sedentary piscine predators. If the predatory species exhibits limited movement from the point of consumption (i.e., remains between successive arrays), no bias will be introduced to the detection history. Conversely, even predators who are mobile through the study site may introduce no bias in the detection history in the event the predator regurgitates or excretes the ingested tag prior to detection. With respect to analyses of unidirectional migration survival, predation bias also would not be introduced in the event a predator, along with the ingested tag, moves in the opposite direction (e.g. upstream, in the case of this study) as in the detection history example presented in Fig. 7a. Within this study, very little movement was detected post-predation and nearly $63 \%$ of tags signalling as predated were only detected at a single receiver (Fig. 7c, e). Given the high probability of detection at each array, this suggests that predators of these tagged individuals were either highly sedentary, removed tagged smolts from the river, and/or the ingested tags were expelled relatively quickly in comparison to the predator's movement through the estuary (e.g. Fig. 7c-e).

The retention time of tags within predators was unobservable in this study. We can, however, report the time span of post-predated detections, which was approximately 0.75 days on average. This does not compare well with detection histories presented by Daniels et al. [7], nor work presented by Halfyard et al. [8]. In the study by Daniels et al. [7], suspected consumption of tagged individuals suggests that striped bass retained ingested tags for several days to, in some cases, several weeks. However, the tags used in that study (Amirix/Vemco; model V8; $8 \mathrm{~mm}$ diameter by $20.5 \mathrm{~mm}$ length, $2.0 \mathrm{~g}$ in air) are much larger than predator tags which may allow the tag to remain in the gastrointestinal tract of the predator longer, especially if tags are passed as opposed to regurigitated. Halfyard et al. [8] monitored post-predation tag retention times of predator tags within largemouth bass (Micropterus salmoides); retention rates appeared to be negatively correlated with water temperature with the most analogous rate of evacuation generally occurring at more than 4.2 days after being fed tagged rainbow trout (Oncorhynchus mykiss) of similar size to smolts in this study. Estimated retention times reported from Schultz et al. [24] appear to be more in line with what we observed in our study; striped bass fed chinook salmon (Onchorhynchus tshawytscha) with comparably sized tags to those used in our study had observed retention times ranging from 1.2 to 2.7 days. Whilst these observations agree more closely to what we observed this comparatively short retention time occurred in waters much warmer (mean $23.3{ }^{\circ} \mathrm{C}$ ) than temperatures expected in the Miramichi River at this time of year $\left(<18.0{ }^{\circ} \mathrm{C}\right.$; [25]). The small size of the tag not only allows for tagging of smaller individuals but may also allow predators to excrete or regurgitate the consumed tag quicker in relation to larger tags as was potentially the case here. The result of which is a decreased probability of detecting post-predated tags and or a lack of behavioural traits apparent in the detection histories.

Laboratory-based trials have been undertaken for prototype generations of this new tag technology. Two attributes at the forefront of performance are the lag times between the predation event to the switch in signal and the rate of false (positive or negative) switches (i.e. identifies as predated in the absence of predation or fails to identify predation). Trials performed by Halfyard et al. [8] tested two generations of tag prototypes with highly variable performances between the two generations of tags. False-positive triggering was not present in live fish for the first-generation tag but was present in $43 \%$ of second-generation tags. This is not likely to be an issue of consideration within this study as the false triggering observed by Halfyard et al. [7] occurred on average $47( \pm 11.2)$ days post-tagging whilst smolts detected within this study were detected no later than 14 days post-tagging. Furthermore, 3 of 15 (20\%) second-generation tags falsely triggered in dead fish $2-3$ days postmortem. As such, the potential of falsely triggered tags exists for smolts registered as predated within this study. 


\section{a Predation signalled}

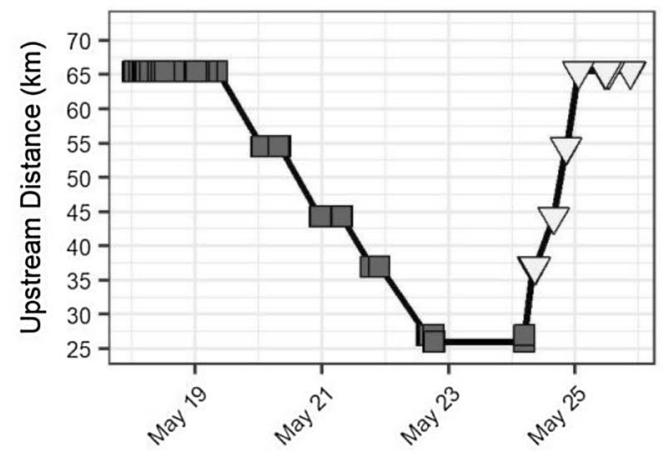

Date

\section{Predation signalled}

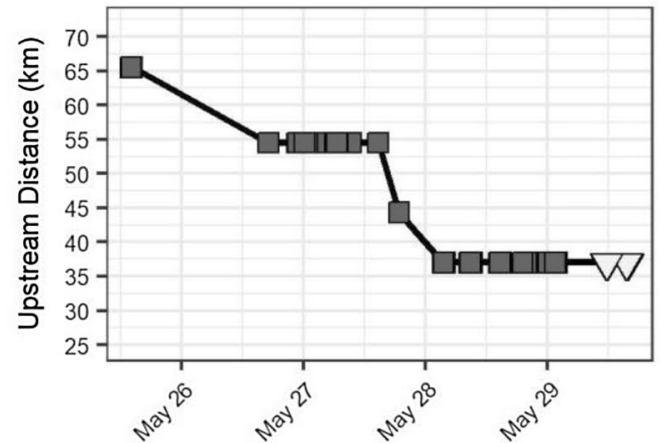

Date

\section{e Predation signalled}

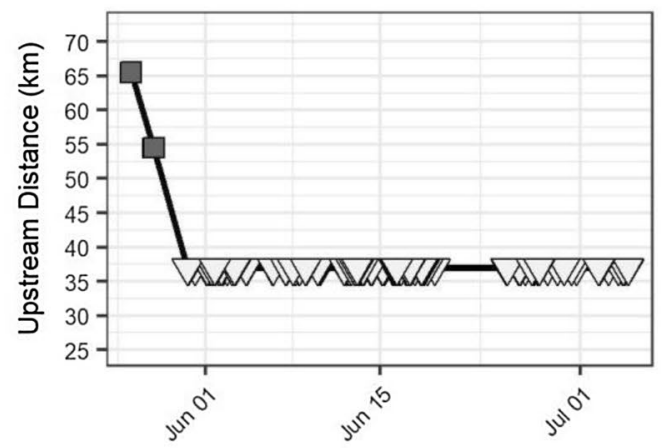

Date b Predation not signalled

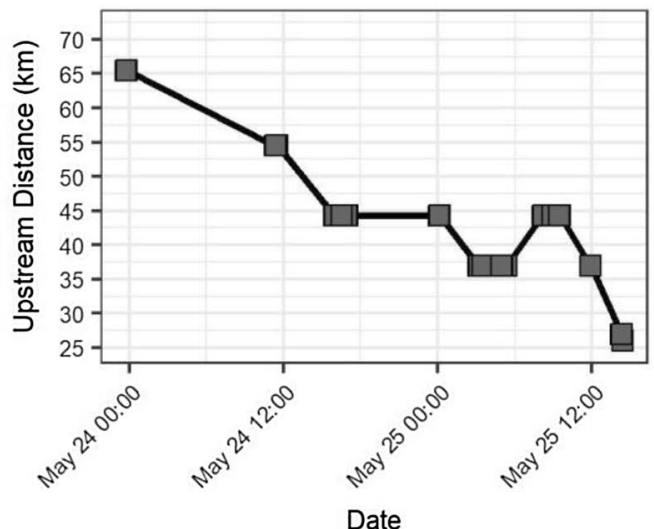

d Predation not signalled

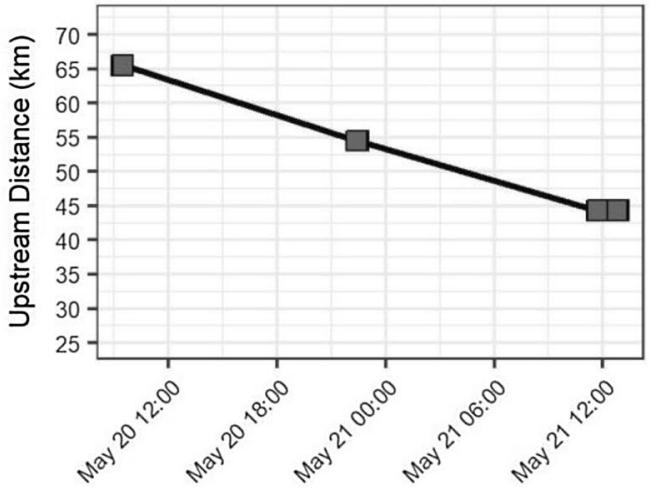

Date
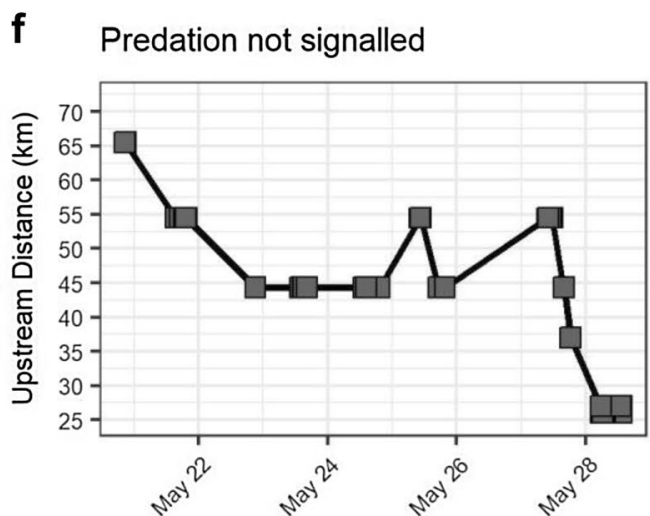

Date

Fig. 7 Example movement: symbols represent the time and the kilometer position within the study site for six example detection histories. Grey squares are detections where predation has not been identified. White triangles represent detections where predation has been identified

Only $6 \%$ of all tags tested by Halfyard et al. [8] failed to trigger following a predation event. The authors highlighted potential links between signal lag times and falsepositive switches. More recent validation of the current production version of predator tags suggests that signal lag times are more similar to those of the second-generation tags. This most recent experiment utilized the same species as were involved in the study performed by 
Halfyard et al. [8] at a temperature of $13{ }^{\circ} \mathrm{C}$ and observed a lag time of $5.8 \mathrm{~h}$ ( $\mathrm{sd}=2.6 \mathrm{~h}$; Webber, unpublished).

Regardless of some draw backs to these tags, the empirical fashion in which predation can be quantified is an obvious benefit over behaviour-based models. Predator tags may allow us to gain insights into the locations and rates of predation. There is, however, an inability to discern between species' and types of predators responsible. To develop a robust understanding of predator interactions and reduce uncertainty from any classifier, ideally future studies would incorporate both predator tags and behaviour-based classifiers. Unfortunately, the spatial resolution in relation to the post-predated detections did not allow for the incorporation of an adequate behaviour-based model here. In the event, receiver array densities were higher throughout the estuary, post-predated behaviours may have been more apparent.

\section{Conclusion}

Estimated survival presented the greatest predation bias which peaked within the upper NW estuary and gradually declined to nearly no apparent bias before the beginning of the Miramichi Bay as predated tags failed through time to be detected. This is most likely due to tag expulsion from the predator between or upstream of the receiver arrays. Whilst we have demonstrated that predation can bias telemetry results, it appeared to be rather short-lived given the apparent retention times of these tags within the predators introducing the bias. This statement however is unlikely to be transferable to other systems, years, target species and predatory species. As such, the effects of the species and densities of predators, their general behaviours, ingested tag retention times, and other relevant variables in relation to bias must be considered for any telemetry project.

\section{Abbreviations}

GoSL: Gulf of St. Lawrence; KDE: kernel density estimate; MCMC: Markov Chain Monte Carlo; NW: Northwest Miramichi River.

\section{Acknowledgements}

We thank Mark Hambrook and staff of the Miramichi Salmon Association for their assistance with fieldwork.

\section{Authors' contributions}

JD and JC conceived the study. JD designed the study, performed the experiment and analysed the data. JD, JC, SS, and DW wrote the paper. All authors read and approved the final manuscript.

\section{Funding}

The Department of Fisheries and Oceans Canada Atlantic Salmon Research Joint Venture Foundation provided funding for predator tags and receivers.

\section{Availability of data and materials}

The data and computational codes used in the current study are available from the corresponding author upon reasonable request.
Ethics approval and consent to participate

The study was approved by the Department of Fisheries and Oceans Canada Maritimes and Gulf Region in accordance with the Canadian Council on Animal Care.

\section{Consent for publication}

Not applicable.

\section{Competing interests}

The authors declare that they have no competing interests.

\section{Author details}

${ }^{1}$ Atlantic Salmon Federation, 15 Rankine Mill Road, Chamcook, NB E5B 3A9, Canada. ${ }^{2}$ AmirixNemco, 20 Angus Morton Drive, Bedford, NS B4B 0L9, Canada.

Received: 18 April 2019 Accepted: 26 August 2019

Published online: 10 September 2019

\section{References}

1. Hussey NE, Kessel ST, Aarestrup K, Cooke SJ, Cowley PD, Fisk AT, Harcourt RG, Holland KN, Iverson SJ, Kocik JF, Flemming JE. Aquatic animal telemetry: a panoramic window into the underwater world. Science. 2015;348(6240):1255642.

2. Romine JG, Perry RW, Johnston SV, Fitzer CW, Pagliughi SW, Blake AR. Identifying when tagged fishes have been consumed by piscivorous predators: application of multivariate mixture models to movement parameters of telemetered fishes. Anim Biotelemetry. 2014;2(1):3.

3. Adams NS, Rondorf DW, Evans SD, Kell JE, Perry RW. Effects of surgically and gastrically implanted radio transmitters on swimming performance and predator avoidance of juvenile Chinook salmon (Onchorhynchus tshawytscha). Can J Fish Aquat Sci. 1998;55:781-7.

4. Gibson AJ, Halfyard EA, Bradford RG, Stokesbury MJ, Redden AM. Effects of predation on telemetry-based survival estimates: insights from a study on endangered Atlantic salmon smolts. Can J Fish Aquat Sci. 2015;72(5):728-41.

5. Beland KF, Kocik JF, Sheehan TF. Striped bass predation upon Atlantic salmon smolts in Maine. Northeast Nat. 2001;8(3):267-75.

6. Melnychuk MC, Christensen V, Walters CJ. Meso-scale movement and mortality patterns of juvenile coho salmon and steelhead trout migrating through a coastal fjord. Environ Biol Fishes. 2013;96:325-39.

7. Daniels J, Chaput G, Carr J. Estimating consumption rate of Atlantic salmon smolts (Salmo salar) by striped bass (Morone saxatilis) in the Miramichi River estuary using acoustic telemetry. Can J Fish Aquat Sci. 2018;75(11):1811-22

8. Halfyard EA, Webber D, Del Papa J, Leadley T, Kessel ST, Colborne SF, Fisk AT. Evaluation of an acoustic telemetry transmitter designed to identify predation events. Methods Ecol Evol. 2017;8(9):1063-71.

9. Chaput G, Carr J, Daniels J, Tinker S, Jonsen I, Whoriskey F. Atlantic salmon (Salmo salar) smolt and early post-smolt migration and survival inferred from multi-year and multi-stock acoustic telemetry studies in the Gulf of St. Lawrence, northwest Atlantic. ICES J. Marine Sci. 2019;76:1107-21.

10. DFO. Atlantic Salmon (Salmo salar) returns to the Miramichi River (NB) for 2012. 2013. Report No.: 2013/009. http://www.dfo-mpo.gc.ca/csas-sccs/ Publications/ScR-RS/2013/2013_009-eng.pdf.

11. Hayward J, Sheasgreen J, Douglas S, Reid J. Diadromous fish monitoring programs in the Miramichi River system in 2011. 2014. http://epe.lac-bac. gc.ca/100/201/301/weekly_checklist/2014/internet/w14-39-U-E.html/ collections/collection_2014/mpo-dfo/Fs97-4-3042-eng.pdf. Accessed 10 Sept 2018.

12. Chaput G, Douglas SG, Hayward J. Biological characteristics and population dynamics of Atlantic Salmon (Salmo salar) from the Miramichi River, New Brunswick, Canada. Canadian Science Advisory Secretariat Research Document 2016/029:v-53; 2016.

13. Meredith M, Ridout M. Overlap: estimates of coefficient of overlapping for animal activity patterns. 2018; 0.3.2 edition, http://CRAN.Rproject.org/ package $=$ overlap.

14. R Core Team. R: a language and environment for statistical computing. 2016. http://www.R-project.org/. 
15. Kéry M, Schaub M. Bayesian population analysis using WinBUGS: a hierarchical perspective. New York: Academic Press; 2011

16. Royle JA. Modeling individual effects in the Cormack-Jolly-Seber model: a state-space formulation. Biometrics. 2008;64(2):364-70.

17. DFO. Spawner abundance and biological characteristics of striped bass (Morone saxatilis) in the Southern Gulf of St. Lawrence in 2015. Science Response. 2016. http://publications.gc.ca/collections/collection_2016/ mpo-dfo/Fs70-7-2016-017-eng.pdf.

18. DFO. Spawner abundance and biological characteristics of striped bass (Morone saxatilis) in the southern Gulf of St. Lawrence in 2017. 2018. http://waves-vagues.dfo-mpo.gc.ca/Library/40689402.pdf.

19. Halfyard EA, Gibson AJ, Ruzzante DE, Stokesbury MJ, Whoriskey FG. Estuarine survival and migratory behaviour of Atlantic salmon Salmo salar smolts. J Fish Biol. 2012;81(5):1626-45.

20. Handeland SO, Järvi T, Fernö A, Stefansson SO. Osmotic stress, antipredator behaviour, and mortality of Atlantic salmon (Salmo salar) smolts. Can J Fish Aquat Sci. 1996;53:2673-80.

21. McCormick SD, Hansen LP, Quinn TP, Saunders RL. Movement, migration, and smolting of Atlantic salmon (Salmo salar). Can J Fish Aquat Sci. 1998:55(Suppl 1):77-92.
22. McCormick SD, Moriyama S, Björnsson BT. Low temperature limits photoperiod control of smolting in Atlantic salmon through endocrine mechanisms. Am J Physiol. 2000;278:1352-61.

23. Thorstad EB, Whoriskey F, Uglem I, Moore A, Rikardsen AH, Finstad B. A critical life stage of the Atlantic salmon Salmo salar: behaviour and survival during the smolt and initial post-smolt migration. J Fish Biol. 2012:81(2):500-42.

24. Schultz AA, Kumagai KK, Bridges BB. Methods to evaluate gut evacuation rates and predation using acoustic telemetry in the Tracy Fish Collection Facility primary channel. Anim Biotelemetry. 2015;3(1):13.

25. Caissie D, Breau C, Hayward J, Cameron P. Water temperature characteristics within the Miramichi and Restigouche rivers. DFO Can Sci Advis Secret. 2013;2012(165):6-31.

\section{Publisher's Note}

Springer Nature remains neutral with regard to jurisdictional claims in published maps and institutional affiliations.
Ready to submit your research? Choose BMC and benefit from:

- fast, convenient online submission

- thorough peer review by experienced researchers in your field

- rapid publication on acceptance

- support for research data, including large and complex data types

- gold Open Access which fosters wider collaboration and increased citations

- maximum visibility for your research: over $100 \mathrm{M}$ website views per year

At $\mathrm{BMC}$, research is always in progress.

Learn more biomedcentral.com/submissions 